\title{
A EVOLUÇÃO MORFOLÓGICA E ESTRATIGRÁFICA DE UMA BARREIRA TRANSGRESSIVA/REGRESSIVA NA PLANÍCIE COSTEIRA DO RIO GRANDE DO SUL
}

\author{
THE MORPHOLOGICAL AND STRATIGRAPHIC EVOLUTION OF A TRANSGRESSIVE / \\ REGRESSIVE BARRIER IN THE COASTAL PLAIN OF RIO GRANDE DO SUL
}

\section{Leonardo Gonçalves de LIMA, Cláudia Klose PARISE}

Departamento de Oceanografia e Limnologia, Universidade Federal do Maranhão (UFMA). Av. dos Portugueses, 1966 - Vila

Bacanga, São Luís - MA, E-mails: paleonardo_7@hotmail.com; claudiakparise@gmail.com

\author{
Introdução \\ Controle Regional \\ Métodos \\ Resultados \\ Geologia de Superfície \\ Registros Geofísicos \\ Descrição das Radarfácies \\ Radarfácies Retrogradacionais \\ Radarfácies Progradacionais \\ Sondagens Geológicas \\ Dicussão \\ Conclusões \\ Referências
}

\begin{abstract}
RESUMO - O presente estudo elucida como decorreu a inversão do regime deposicional (transgressivo/regressivo) nos sistemas de barreiras costeiras no setor Torres-Curumim do litoral norte do Rio Grande do Sul. A origem das barreiras costeiras neste setor se deu a partir da implantação de uma unidade transgressiva basal (retrogradacional), diretamente sobre o substrato pleistocênico, sendo sucedida de uma unidade regressiva (progradacional). A transição entre estas unidades antecedeu o ápice da Transgressão Marinha Pós-Glacial (TMP), indicando uma situação de elevado suprimento sedimentar (suprimento > acomodação), o que resultou durante a progradação da barreira costeira, uma fase inicial de regressão normal. Sondagens geotécnicas Standard Penetrating Test (SPT), vibrocore e perfis de Ground-penetrating Radar (GPR) foram utilizados na aquisição de dados estratigráficos do registro sedimentar. Análises sedimentológicas, paleontológicas e geocronológicas foram utilizadas na descrição e interpretação das fácies sedimentares e suas associações. Os primeiros registros da TMP neste setor costeiro, correspondem aos ambientes lagunares que ocuparam a retaguarda da barreira costeira em configuração transgressiva. Canais de ligação viabilizaram a dinâmica entre laguna e oceano o que conduziu a evolução de depósitos estuarinos na retaguarda da barreira. Depósitos de leques de sobrelavagem, deltas de maré enchente e dunas transgressivas foram identificados como os modos operantes da transferência de sedimentos em direção ao continente. Estes mesmos depósitos afloram no setor oceânico da barreira representam a área fonte sedimentar requerida para a barreira executar sua migração em direção do continente. Este deslocamento da barreira terminou por restringir o espaço de acomodação na retrobarreira, dando início à inversão do regime deposicional transgressivo/regressivo, e por consequência interrompe os eventos de sobrelavagem e a dinâmica dos canais de ligação. $\mathrm{O}$ isolamento completo da retrobarreira (lagunar/estuarina) deu início a fase regressiva (progradacional) da barreira antes de ter sido atingido o nível mais alto da TMP (máximo eustático). Esta situação tipifica a fase inicial de progradação como uma regressão normal. No entanto, ao término da TMP o nível relativo do mar finalmente iniciou seu rebaixamento provocando uma regressão forçada que persiste até os dias atuais.
\end{abstract}

Palavras-chave: Barreiras Costeiras; Sondagens Geológicas; Ground-penetrating Radar.

\begin{abstract}
The present study sheds light on the reversal of the transgressive/regressive depositional regime in the coastal barrier systems in the Torres-Curumim sector of the north coast of Rio Grande do Sul state. The origin of the coastal barriers in this sector came from the establishment of a basal transgressive (retrogradational) unit, directly on the pleistocene substrate, succeeding from a regressive (progradational) unit. The transition between these units preceded the apex of the last Post-Glacial Marine Transgression (PMT), indicating a situation of high sedimentary supply (supply > accommodation space), which in turn was preserved during the coastal barrier progradation as a normal regression phase. Geotechnical surveys such as Standard Penetrating Test (SPT), vibrocore and Ground-Penetrating Radar (GPR) profiles were used to acquire stratigraphic data from the sedimentary record. Sedimentological, paleontological and geochronological analyzes were used to describe and interpret sedimentary facies and their associations. The first records of PMT in this coastal sector corresponded to the lagoon environments that occupied the rear of the transgressive coastal barrier. Inlets have enabled the lagoon-ocean dynamics, which led to the evolution of estuarine deposits at the rear of the barrier. Washover fan deposits, flood tide deltas and transgressive dunes have been identified as the leading modes of sediment transfer towards the continent. These same deposits in the oceanic sector of the barrier represent the sedimentary source area required for the barrier to migrate to the mainland. This displacement of the barrier ends by restricting the accommodation space in the rear barrier, initiating the inversion of the transgressive/regressive depositional regime, and consequently interrupting the overwashing events and the dynamics of the binding channels. The complete isolation of the backbarrier (lagoon/estuarine) initiated the regressive (progradational) phase of the barrier before the highest PMT (maximum eustatic) level has been reached. Such a situation typifies this early phase of progradation as a normal regression. However, at the end of the PMT, the relative sea level finally begins to decrease causing a forced regression that persists until the present day.
\end{abstract}

Keywords: Coastal Barrier; Geological Survey; Ground-penetrating Radar.

São Paulo, UNESP, Geociências, v. 39, n. 3, p. 709 - 725, 2020 


\section{INTRODUÇÃO}

A morfologia e as fácies sedimentares associadas a sistemas de barreiras costeiras dependem de fatores como o clima, o suprimento sedimentar, o regime de ondas e marés, a topografia antecedente e as variações do Nível Relativo do Mar (NRM) (Kraft \& John, 1979). A interação entre estes fatores produz diferentes padrões de empilhamento estratigráfico, resultando em barreiras transgressivas, regressivas e estacionárias. Os primeiros modelos estratigráficos de barreiras costeiras foram baseados em estudos de sondagens realizados principalmente na década de 1970. As seções estratigráficas idealizadas das fácies de barreiras produzidas a partir desses estudos não incluíam as complexas relações de fácies comuns à maioria das barreiras costeiras (Galloway \& Hobday, 1996). Avanços recentes como o Groud-penetrating Radar (GPR) levaram a uma maior precisão e detalhamento na descrição dos modelos estratigráficos de barreiras e de sua variabilidade (Van Heteren et al., 1996; Smith et al., 1999; Fitzgerald \& Van Heteren, 1999).

Durante as transgressões, menos sedimento é preservado quando comparado às regressões, isto porque a erosão na antepraia ou em canais de ligação remove parte do sedimento previamente depositado. O resultado disso é o predomínio de inconformidades no registro, principalmente superfícies erosivas. A primeira dessas superfícies em direção ao continente marca a transgressão dos complexos lagunares na planície costeira, a segunda marca a extensão basal dos depósitos transgressivos, geralmente definida por uma superfície de erosão também conhecida como ravinamento (superfície de ravinamento - SR). O maior problema no reconhecimento dos depósitos transgressivos em sub-superfície centra-se no fato de que a transgressão erode a linha de costa e a antepraia, resultando na destruição da parte superior da sequência transgressiva. Portanto, a transgressão pode ocorrer sobre diversas variantes de terreno e de ambientes de planícies costeiras de idades anteriores. Fisher (1961) explanou que o avanço do mar frente a uma transgressão contínua poderia destruir completamente o registro transgressivo.

Belknap \& Kraft (1981) sintetizaram em um modelo os fatores primordiais determinantes do potencial de preservação de sequências deposicionais costeiras transgressivas, cujo principal mecanismo de preservação é condicionado pela profundidade de erosão da antepraia, frente à topografia antecedente inundada pelo mar transgressivo. Belknap \& Kraft (1985) demonstraram que além destes fatores citados, a topografia antecedente afeta substancialmente o desenvolvimento de barreiras costeiras pelo controle regional da declividade, arranjando baias e a localização de canais de ligação. Assim, é esperado que mudanças sutis na combinação destes fatores de controle possam modificar bruscamente a natureza dos depósitos de barreiras costeiras. Este nível de complexidade, segundo Kraft \& John (1979), resulta na improbabilidade da existência de um conjunto de parâmetros ou sequências que consiga identificar se uma barreira é transgressiva ou regressiva a partir de um único ponto de controle ou apenas baseado em dados geomorfológicos.

Muitos estudos focam sobre a natureza das respostas das linhas de costa submetidas à alteração do NRM. Carter \& Orford (1993), por exemplo, ilustram a diversidade de mudanças que ocorrem na plataforma continental e nas barreiras costeiras durante a ascensão do nível do mar no Holoceno e as implicações destes níveis em sistemas de barreiras associadas a costas de baixo declive. Da mesma forma, estes padrões evolutivos mesmo sob um NRM estável são extremamente complexos, envolvendo a formação de canais de ligação, erosão diferenciada e sobrelavagem (Oertel, 1985; Woodroffe, 2002).

A atenção sobre o efeito da última TMP em sistemas costeiros modernos produziu abundante informação sobre os mecanismos que regem os depósitos transgressivos (Curray, 1964). Exclusivamente, os depósitos recentes são o ponto chave na conexão entre espaço de acomodação e suprimento sedimentar. Isto, devido ao contemplamento da arquitetura tridimensional de sequências da margem continental dentro de um contexto de nível do mar conhecido, como também de dados oceanográficos e paleooceanográficos, conectando os processos deposicionais com a fisiografia atual.

A arquitetura interna dos depósitos atuais permite uma melhor compreensão das prováveis taxas cujas sequências pretéritas foram deposi- 
tadas e para as quais o controle de tempo é limitado, tanto em precisão como em resolução.

$\mathrm{O}$ estudo da última TMP oferece diversas vantagens ao entendimento de transgressões anteriores, incluindo o controle cronoestratigráfico por meio de abundante material para datação, amostragem intensiva, recuperação de sessões rasas, imageamento sísmico de alta resolução, e o conhecimento sobre características da bacia de drenagem.

Desta forma, o presente estudo analisa a evolução costeira de um segmento litorâneo cuja arquitetura estratigráfica observada e, portanto, sua preservação se deve ao fato de a barreira transgressiva encontrar-se estabelecida no momento de máximo deslocamento da TMP. Tal contexto estratigráfico foi aqui estudado com o intuito de entender como os litorais transgressivos moldaram as atuais configurações dos sistemas de barreiras costeiras. Sua identificação é crucial para a determinação do modo dominante de transferência de sedimentos em direção ao continente, imposto pelas barreiras transgressivas, e em direção ao oceano, pelas barreiras regressivas.

\section{CONTROLE REGIONAL}

A localização da Planície Costeira do Rio Grande do Sul (PCRS) a insere na faixa latitudinal sujeita ao clima subtropical úmido, sob influência da massa de ar tropical, governada pelo Anticiclone Semi-Permanente do Atlântico Sul e pela massa de ar polar, modulada pelo Anticiclone Móvel Polar. Esses dois centros de ação controlam não só a temperatura do ar, resultando em verões muito quentes e invernos rigorosos, como também o regime de ventos em superfície, forçante fundamental na morfogênese de planícies costeiras.

O regime de ventos, na região é de alta energia, e de natureza bimodal. A direção predominante dos ventos é de nordeste, associado à borda do Anticiclone do Atlântico Sul, estando mais ativo na primavera e no verão. O vento secundário, associado à atividade do Anticiclone Móvel Polar, incide de O-SO e torna-se mais atuante no outono e inverno (Cavalcanti et al., 2009).

O estado apresenta índices pluviométricos médios em torno de $1300 \mathrm{~mm}$, com as chuvas bem distribuídas ao longo do ano (Nimer, 1990).

A costa do Rio Grande do Sul apresenta um regime de micro marés onde o transporte e a deposição de sedimentos são dominados pela ação das ondas e correntes litorâneas a elas associadas (Tomazelli \& Villwock, 1992) e as marés metereológicas de até $1,9 \mathrm{~m}$ (Parisi et al., 2009). O regime de ondas é caracterizado pela ocorrência de uma ondulação (swell waves) de longo período proveniente de SE e por vagas locais (sea waves) provenientes principalmente de E-NE, com altura significativa de ondas de 1,5 m (Motta, 1967). Especialmente durante os meses de outono e inverno, o regime normal de ondas é episodicamente perturbado pela ocorrência de ondas de tempestade (storm waves) associadas à passagem de frentes frias provenientes do sul (Calliari et al., 1996).
A PCRS corresponde à morfologia da parte proximal, emersa, da Bacia de Pelotas, uma bacia marginal aberta que, como consequência dos processos de abertura e expansão do Atlântico Sul, desenvolveu-se no extremo sul da margem continental brasileira. Esta bacia acumulou um pacote de sedimentos dominantemente siliciclásticos que alcança, em seu depocentro, uma espessura superior a $12 \mathrm{~km}$ (Fontana, 1996).

Os depósitos sedimentares acumulados na PCRS são provenientes da erosão de rochas ígneas e metamórficas pré-cambrianas do Escudo Uruguaio-Sul-Rio-Grandense das rochas sedimentares e vulcânicas da Bacia do Paraná, de idade paleozoica e mesozoica (Figura 1).

A plataforma continental adjacente à planície costeira alcança uma largura média de cerca de 150 $\mathrm{km}$ e é coberta principalmente por sedimentos clásticos terrígenos com concentrações de cascalho biodetrítico (Martins et al., 1967). A plataforma interna é, na sua maior parte, coberta por areias terrígenas de composição e textura muito semelhantes aos sedimentos praiais adjacentes.

De acordo com Villwock et al. (1986), a PCRS se desenvolveu sob o controle de dois tipos principais de sistemas deposicionais: (1) um sistema de leques aluviais, que ocupa a parte mais interna da planície costeira, resultantes de processos de transporte associados aos ambientes de encosta, e (2) quatro distintos sistemas deposicionais transgressivos-regressivos do tipo laguna-barreira (Figura 1), sendo três de idade pleistocênica e um de idade holocênica (Villwock et al., 1986).

A preservação destes sistemas deposicionais não foi a mesma, ora preservando suas fases transgressivas, ora preservando regressivas ou até mesmo ambas as sequências. Exemplo disto pode ser verificado na barreira I cuja origem está associada ao retrabalhamento da porção distal de 
leques aluviais em contexto unicamente transgressivo ou mesmo tendo sua fase regressiva destruída pelo ciclo posterior.

O segundo ciclo foi responsável pela construção da barreira arenosa que isolou a Lagoa dos Patos e a Lagoa Mirim (barreira II) novamente sob um contexto transgressivo. O terceiro ciclo adicionou mais um sistema do tipo laguna-barreira (barreira III) esta, preservada em ambos os seus contextos deposicionais (transgressiva/regressiva).

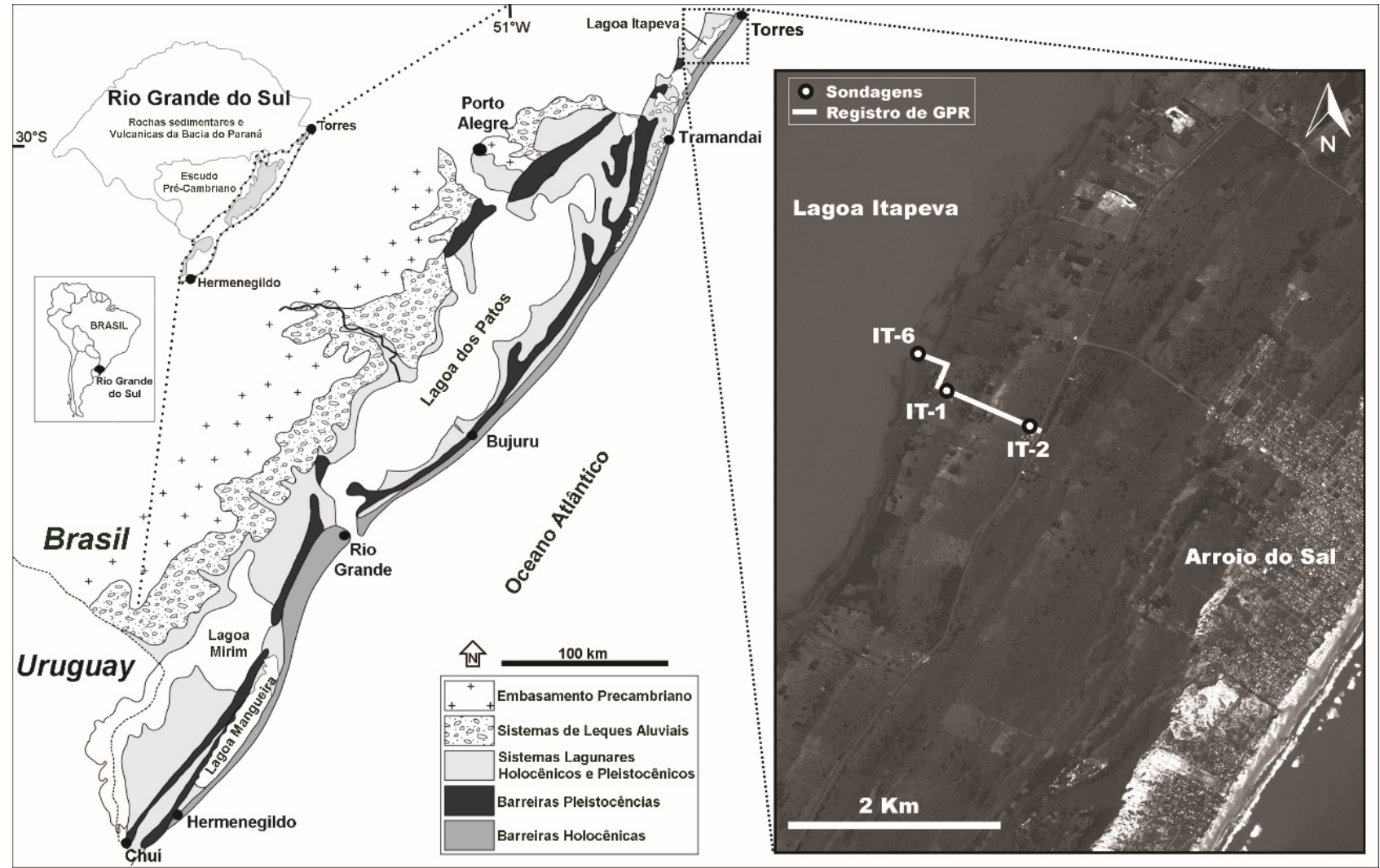

Figura 1 - Localização da Praia de Arroio do Sal e a geologia regional da Planície Costeira do Rio Grande do Sul (modificado de Tomazelli \& Villwock, 1996). A imagem Spot1 ilustra a superfície da barreira costeira moderna com dunas costeiras dominando a barreira costeira. A localização da seção transversal a Praia de Arroio do Sal indicando a posição das sondagens e perfilagem com GPR.

O sistema deposicional mais recente do tipo laguna-barreira da PCRS (barreira IV) desenvolveu-se durante o Holoceno, e da mesma forma que o sistema anterior (barreira III) não apresenta a mesma natureza morfológica ao longo da costa. Dillenburg et al. (2000) propôs que, em uma escala de longo período, setores costeiros correspondentes a reentrâncias e projeções costeiras refletem a topografia antecedente, constituindo-se, portanto, em uma herança geológica. Sutis variações no declive da plataforma continental, ao longo da costa do RS, são acompanhadas por variações da orientação da linha de costa. Quando a configuração desta última muda de côncava para convexa (projeção costeira), o gradiente da plataforma apresenta-se mais íngreme. De modo inverso, quando a linha de costa muda de convexa para côncava (reentrância costeira), o declive da plataforma interna apresenta-se mais suave. Nas reentrâncias e projeções costeiras, desenvolvem-se respectivamente, barreiras regres- sivas e transgressivas.

A barreira holocênica da PCRS é formadas basicamente por areias quartzosas, finas a muito finas (Martins, 1967), e que apresentam, em certos locais, elevadas concentrações de minerais pesados (Dillenburg et al., 2004). O campo de dunas eólicas é bem desenvolvido, com uma largura variável de 2 a $8 \mathrm{~km}$. Areias finas a muito finas, lamas e turfas heterogêneas são os principais sedimentos acumulados nos diversos ambientes deposicionais componentes do sistema lagunar holocênico.

No Brasil, assim como ao redor do globo, há um consenso quanto ao comportamento do nível do mar durante o Pleistoceno Tardio/Início do Holoceno. A última transgressão teve início há cerca de 17.500 anos AP quando o NRM estava aproximandamente $130 \mathrm{~m}$ abaixo do atual. Após isto o nível do mar subiu com taxas de $1,2 \mathrm{~cm} / \mathrm{ano}$, variando de $0,6 \mathrm{~cm} / \mathrm{ano}$ (14.000 a 12.000 anos AP) para $1,9 \mathrm{~cm} /$ ano (8.000 a 6.500 anos AP) (Correa et al., 1995). Não existem dados confiáveis a 
respeito das mudanças do NRM para o Holoceno Médio a Tardio no litoral do RS.

No entanto, as curvas de NRM obtidas para uma região costeira, distante cerca de $130 \mathrm{~km}$ ao norte do RS mostram o nível de mar mais alto da TMP ocorrente há cerca de 6.000-5.000 anos AP, quando o NRM chegou a poucos metros ( 1 a $3 \mathrm{~m}$ ) acima do seu nível atual (Figura 2), seguido por uma declínio contínuo até os dias atuais (taxas de 0,4 mm/ano) (Martin et al., 2003; Angulo et al., 2006).

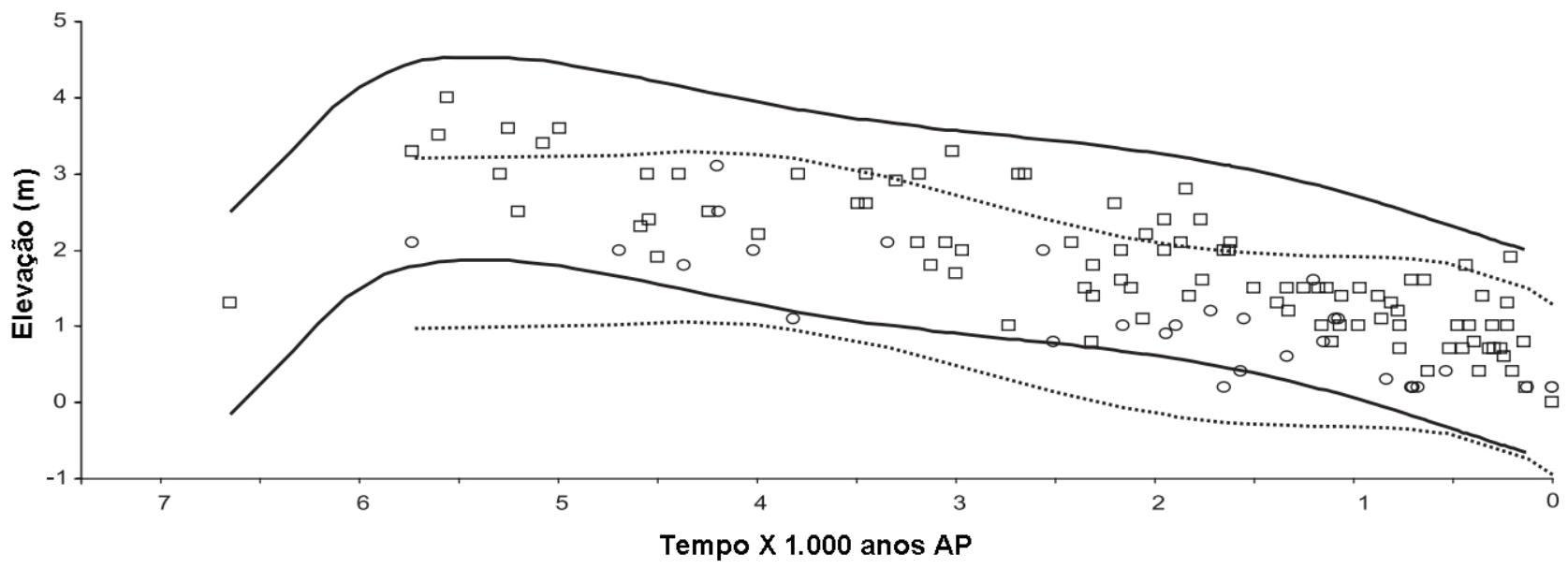

Figura 2 - Envelope do NRM e paleoreconstrução do NRM para a costa brasileira ao norte de $28^{\circ}$ (linha sólida e quadrados) e ao sul de $28^{\circ}$ (linha pontilhada e círculos), baseado em amostragens de vermetídeos (modificado de Angulo et al., 2006).

\section{MÉTODOS}

Este estudo é baseado em registros de GPR (Ground-penetrating Radar), análises de fácies sedimentares e datações de radiocarbono. Os registros de GPR foram obtidos usando um módulo de aquisição SIR-3000 GSSI (Geophysical Survey Systems, Inc.) com uma antena de $200 \mathrm{MHz}$ de frequência central em arranjo Common Off Set.

$\mathrm{O}$ registro geofísico foi interpretado baseando-se na sismoestratigrafia adaptada para registros de GPR (Neal, 2004). Orientada pelos registros de GPR, foram executadas 2 sondagens SPT (Standard Penetrating Test) e 1 sondagem vibrocore.

A técnica (SPT) é regulamentada no Brasil pela normativa NBR-6468 da ABNT/CB (Associação Brasileira de Normas Técnicas/Comitê Brasileiro de Construção Civil) e consiste basicamente em uma medida de resistência dinâmica, conjugada a uma sondagem de reconhecimento sedimentar. Esta permite acessar grandes profundidades, porém de forma descontínua, isto é, a cada metro sondado obtêmse a recuperação de $45 \mathrm{~cm}$ de registro sedimentar intacto (não perturbado) e $55 \mathrm{~cm}$ de registro sedimentar perturbado (amostra de calha).

A extração das amostras intactas é realizada à percussão de um peso batente $(65 \mathrm{~kg})$ sobre hastes de penetração conectadas ao amostrador do tipo RAYMOND/TERZAGHI. A penetração deste amostrador fornece um índice (índice $=n^{\circ}$ golpes/penetração do amostrador) de compactação do depósito sedimentar. A extração das amostras perturbadas $(55 \mathrm{~cm})$ é realizada por meio da perfuração manual com um trépano auxiliado de circulação de água com bentonita.

A sondagem vibrocore foi realizada pela penetração de um cano de alumínio de 7,5 cm de diâmetro e $6 \mathrm{~m}$ de comprimento mediante a vibração de baixa frequência (amplitude de vibração 0,85 mm a $12.500 \mathrm{RPM}$ ).

Tanto as sondagens como a aquisição de GPR foram aferidas com um DGPS marca Leica Viva CS15, e correlacionadas ao ponto médio de espraiamento das ondas na praia de Rondinha Nova e corrigido pela tábua de maré (DHN, 2011) para o Porto de Imbituba - SC, situado cerca de $130 \mathrm{~km}$ ao norte da área de estudo.

O pós-processamento dos dados de GPR foi executado nos softwares RADAN 6.6 e ReflexW. O ajuste da constante dielétrica foi definido pela correlação entre a interface geotécnica (compactação dos depósitos) da litofácies eólico/praial e sua correspondente radarfácies eólico/praial.

As análises granulométricas foram realizadas num analisador de partículas a laser CILAS (modelo 1180). O tratamento estatístico seguiu as técnicas descritas em Folk \& Ward (1957). O carbono total de 40 níveis sedimentares foi avaliado segundo método empregado por Wetzel (1975). Os aspectos relativos à cor das amostras 
sedimentares seguiram os parâmetros descritos em Munsell (2009).

Análises de ${ }^{14} \mathrm{C}$, segundo o método Accelerator Mass Spectrometry (AMS), foram realizadas em dois tipos de materiais: concha de moluscos e sedimentos orgânicos, sendo realizadas no laboratório Beta Analytics
Radiocarborn Dating Laboratory em Miami, Flórida, EUA.

A calibração das amostras seguiu a base de dados MARINE04 (Hughem et al., 2004) e INTCAL04 (Reimer et al., 2004) interpolados segundo o ajuste ponderado de spline cúbico descrito em Talma \& Vogel (1993).

\section{Geologia de Superfície}

Os limites entre o embasamento rochoso (Formação Serra Geral/Botucatu) e a Planície Costeira do Rio Grande do Sul (PCRS) ocorrem na margem noroeste da Lagoa Itapeva (Figura 1). Neste setor costeiro verifica-se a maior declividade entre a cabeceira do sistema de drenagem fluvial e sua foz lagunar de toda a PCRS.

Remanescentes de cordões litorâneos pleistocênicos ancorados na formação Serra Geral são seccionados pelo Rio Três Forquilhas que tem sua foz na Lagoa Itapeva. Sua elevada carga sedimentar ocasiona o avulsionamento do canal principal preservando antigas barras de desembocadura.

De modo geral ambas as margens da Lagoa Itapeva são amplamente vegetadas tanto por banhados como por matas paludosas. Na posição central da margem leste da barreira destaca-se a presença de um pontal arenoso definido por Lima (2012) como um remanescente de um leque de sobrelavagem originado quando a barreira costeira se apresentava em configuração essencialmente transgressiva no Holoceno Médio.

A superfície da barreira costeira na Praia de Itapeva é dominada de feições interdunas que Hesp et al. (2007) denominaram de planícies de areia pantanosa, campos de nebkha e planícies de deflação com cotas de +6 m em relação ao NRM, que na proximidade da lagoa se mostram na maior parte do tempo alagadas. Cotas topográficas mais elevadas e relacionadas às dunas transgressivas junto à margem controlam esta morfologia alagadiça dificultando o escoamento pluvial em direção à Lagoa Itapeva.

Na posição central da barreira, aproximadamente sobre a rodovia RS-389, inicia-se um compartimento de cordões de dunas descontínuas identificadas como antigas cristas de dunas transgressivas que hoje, apresentam-se tomadas pela vegetação (Hesp et al., 2007). A tendência de elevação em direção ao centro da barreira (RS-389) é, segundo Hesp et al. (2007), uma fase de agradação e progradação da barreira, ocorrida entre 8.000 - 7.000 anos AP e 5.600 anos AP (máximo eustático).

Anexada à praia, se desenvolve a atual (moderna) fase de formação de dunas transgressivas, que compõe, junto com a duna frontal, o compartimento eólico ativo (atual) da barreira, e que ocupa de forma contínua, ao longo da costa (NE-SO), uma faixa de $1,5 \mathrm{~km}$ a partir da praia.

Na face praial, em cortes de drenagem pluvial (sangradouros), pode-se observar a ocorrência de laminações cruzadas de baixo ângulo indicativas do estirâncio em cotas de $+1,4$ m acima do NRM.

\section{Registros geofísicos}

O radar de penetração de solo (GPR) tem sido utilizado em regiões costeiras para localizar e identificar estruturas sedimentares (Leatherman, 1987; Jol \& Smith, 1991, Meyers et al., 1994; Bridge et al., 1995; Jol et al., 1996; Bristow et al., 2000; Anthony \& Moller, 2002; Barboza et al., 2009; Dillenburg et al., 2011). Devido à forma de aquisição não-invasiva e de alta resolução, o GPR proporciona um conjunto de dados, muitas vezes único (Neal \& Roberts, 2000). Na interpretação dos dados de GPR é utilizado o termo radar fácies para definir pacotes repetidos de refletores com caráter e geometria semelhante, enquanto seus limites de sequência são determinados pela terminação dos refletores.

De acordo com Van Overmeeren (1998), esta definição envolve as diferenças mapeáveis no padrão de reflexão de uma seção de GPR, ocasionadas por feições com características estruturais e texturais em sub-superfície.

A relativa facilidade no rastreio da radarfácies identificadas neste estudo pelo método de GPR deve-se principalmente ao elevado percentual de minerais pesados (>3\%) encontrados nestes horizontes faciológicos (Buynevich et al., 2004; Lima et al., 2012).

\section{Descrição das Radarfácies}

Rf1-Dunas transgressivas: Esta radarfácies é definida por refletores sub-horizontais, de alta amplitude, lateralmente contínuos, concordantes 
e ondulados de baixa amplitude e alto ângulo $\left(15-20^{\circ}\right)$, com clinoformas curtas e mergulho em direção ao continente, por vezes côncavas. Na proximidade da margem lagunar ocorre o colapso ou dissipação destas clinoformas, restando apenas um perfil ondulado, morfologicamente indefinido (Figura 3).

Rf2-Pós-praia/estirâncio: Refletores lateralmente contínuos, simétricos e concordantes estendendo-se por $30 \mathrm{~m}$ ou mais, de alta amplitude, sub-planares e levemente ondulados, com mergulhos de $3-5^{\circ}$ em direção ao oceano. Este conjunto de refletores apresenta um contado indefinido com a radar fácies superior (Rf1) e inferior (Rf5) (Figura 3).

Rf3-Leque de sobrelavagem: Refletores contínuos, com alta amplitude, concordantes, mergulho (1-8 $)$ em direção ao continente e padrão de terminação em toplap e downlap (Figura 3). .
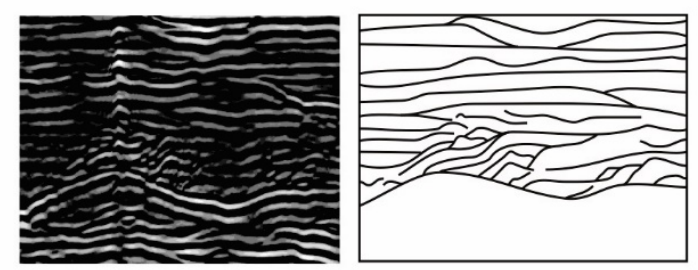

Descontínuo, baixa amplitude, alto ângulo(15-20 $)$, clinoformas

Rf1 curtas com mergulho em direção do continente
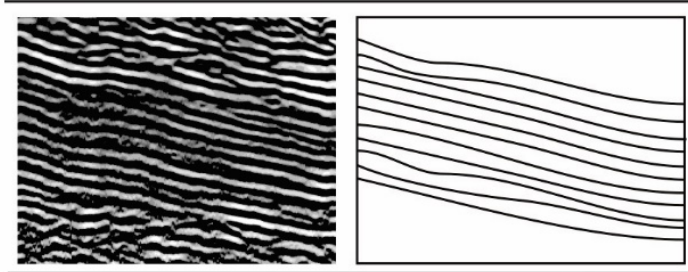

Contínuo, alta amplitude, baixo ângulo $\left(3-5^{\circ}\right)$,

Rf2 com mergulho em direção

Pós-praia/Estirâncio
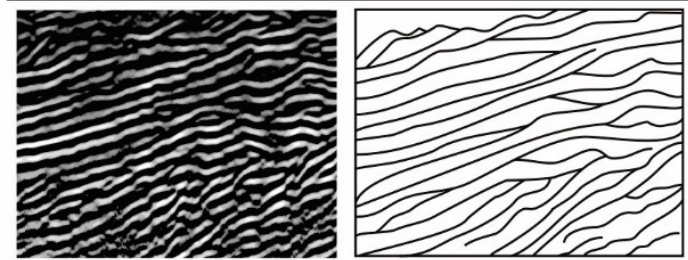
ao oceano
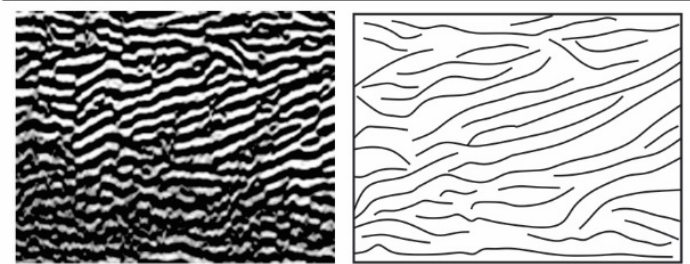

Moderadamente contínuo,

Rf3

alta amplitude,

Leques de sobrelavagem

alto ângulo $\left(1-8^{\circ}\right)$, com mergulho

em direção ao continente
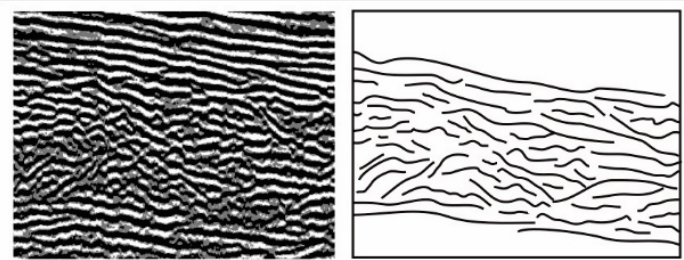

Refletores descontínuos, ondulados, de baixa amplitude e

Rf4 baixo ângulo $\left(3-5^{\circ}\right)$, com mergulho em direção ao continente.

Margem Lagunar

Descontínuo, baixa amplitude,

\section{Rf5}

baixo ângulo $\left(3-5^{\circ}\right)$,com mergulho

Antepraia superior em direção ao oceano

Figura 3 - Interpretação da radarfácies definidas a partir dos perfis de GPR.

Rf4-Margem lagunar: Refletores descontínuos, ondulados, de baixa amplitude e baixo ângulo (3-5) com mergulho em direção ao continente. Ocorrem de forma distinta da Rf3 principalmente pela menor continuidade dos refletores. No limite inferior desta unidade ocorre a atenuação do sinal de GPR, dada a presença de sedimentos finos em sua composição (Figura 3).

Rf5-Antepraia: Apresenta refletores descontínuos, ondulados, de baixa amplitude e baixo ângulo (3-5) e mergulho em direção ao oceano. Ocorrem de forma distinta da $R f 2$ principalmente pela menor continuidade dos refletores. O limite inferior desta unidade não é evidente devido à atenuação do sinal de GPR, em função da presença de sedimentos finos em sua composição (Figura 3)

\section{Radarfácies Retrogradacionais}

O transecto GPR-1 é uma composição de quatro perfis (Figura 4), que interceptam as sondagens IT-1, IT-2 e IT-7. Estes perfis foram corrigidos topograficamente para acomodar um desnível de $5 \mathrm{~m}$ entre os extremos. Este transecto registra a interface entre a radarfácies Rf3 e Rf2, as quais delimitam uma superfície de ravinamento (SR) por ondas sensu Swift, (1975). 
Esta SR foi interpretada como sendo o limiar entre uma fase transgressiva (limite inferior) e uma fase regressiva (limite superior) da barreira costeira, ou seja, representa a interface entre estes dois padrões distintos e antagônicos de deposição sedimentar. Esta SR teve sua origem vinculada à fase transgressiva da barreira costeira quando esta superfície erosiva ainda se encontrava ativa, avançando em direção ao continente e truncando depósitos pré-existentes (leques de sobrelavagem - Rf3) devido à recessão da linha de costa. O registro desta transladação (migração) da SR encontra-se indicado nos sets truncados dos refletores Rf3, os quais demostram por sua vez, que as barreiras transgressivas obtêm as areias diretamente do substrato pela qual elas migram.

Os refletores Rf3 evidenciam o principal aspecto morfológico de uma barreira transgressiva, a deposição de leques de washover (Leatherman, 1983). Estas feições deposicionais ocorrem sempre vinculadas à retaguarda de barreiras costeiras, sendo o ângulo de mergulho de seus refletores usado como indicador da posição da lâmina d'água no momento de sua deposição (Schwartz, 1975). Quando o padrão de reflexão exibe geometrias abruptas (alto ângulo) apontam para uma deposição subaquosa alcançando a retrobarreira, e quando exibem geometrias suaves (baixo ângulo) apontam para uma deposição nas posições subaéreas da barreira costeira. Desta forma é possível individualizar dois tipos de deposição associados a esta radarfácies: Rf3 (washovers fans) quando a deposição alcança a retrobarreira, ocasionando refletores de alto ângulo e a Rf3 (tipical-washover) quando a deposição não alcança a retrobarreira, permanecendo somente sobre a superfície emersa da barreira.

O perfil-A (Figura 4) foi realizado sobre a margem da Lagoa Itapeva interceptando a sondagem IT-7. Sua base ocorre associada a sedimentos lamosos (silte/argila) da deposição lagunar onde o sinal de GPR torna-se impenetrável com antenas de 200 Mhz. Neste perfil pode-se observar a interface entre os sedimentos lagunares (ausência do sinal de GPR) e a radarfácies Rf3 indicando a geometria na qual a Rf3 avança em direção do continente, interditando-se com os sedimentos lagunares. $\mathrm{O}$ conjunto de refletores pertencentes a Rf3 compreende os refletores associados à depo- sição de leques de sobrelavagem e representa a radarfácies diagnóstico da fase transgressiva da barreira costeira. Este padrão de refletores indica a deposição distal dos leques de sobrelavagem adentrando a lâmina d'água do corpo lagunar na retrobarreira (Schwartz, 1982; Murakoshi \& Masuda, 1991; Anthony \& Moller, 2002; Neal et al., 2003). Estes refletores definem antigas posições da margem lagunar no momento de deposição do leque de sobrelavagem. Refletores que mergulham em direção ao continente num contexto de barreiras costeiras são comumente identificados e interpretados como depósitos de leques de sobrelavagem (Shukla et al., 2008; Switzer et al., 2006; Caldas et al., 2006; Moller \& Anthony, 2003).

A radarfácies Rf4 por sua vez é indicativa do retrabalhamento da Rf3 e Rf1 na margem lagunar atual da Lagoa Itapeva. Os refletores Rf1 adentram atualmente a margem onde então, são retrabalhados pela dinâmica de ondas superim-posta pela oscilação do nível d’água da Lagoa Itapeva. A variabilidade do ângulo de mergulho e a presença de refletores internamente truncados definem o padrão da Rf4 (Figura 4).

O perfil-B (Figura 4) apresenta orientação longitudinal à margem da Lagoa Itapeva. Nesta orientação os refletores apresentam-se ondulados alternando refletores nítidos e menos nítidos indicando a variação no teor de sedimentos lamosos (silte + argila) associados à margem lagunar. Nesta deposição um pronunciado refletor na cota $0 \mathrm{~m}$ (NRM) corresponde ao limite entre os depósitos de leques de sobrelavagem (Rf3) e a margem lagunar atual.

O perfil-C (Figura 4) intercepta a sondagem IT-1 e apresenta-se, assim como nos perfis A e $\mathrm{B}$, sobre a fase transgressiva da barreira costeira. A radarfácies Rf3 cobre a base do perfil com refletores contínuos, de baixo ângulo e mergulho em direção do continente. Este padrão exibe uma geometria suavemente côncava e ondulada dos refletores o que indica uma deposição proximal dos leques de sobrelavagem como descrito por Schwartz (1975) e por Neal et al. (2003). Acima disto, refletores Rf4 resultam do retrabalhamento da $R f 1$ na margem lagunar, onde nesta posição ocorrem associados a uma menor incidência de eventos de sobrelavagem e migração de dunas transgressivas possibilitando maior tempo de retrabalhamento pela dinâmica de ondas na margem lagunar. 

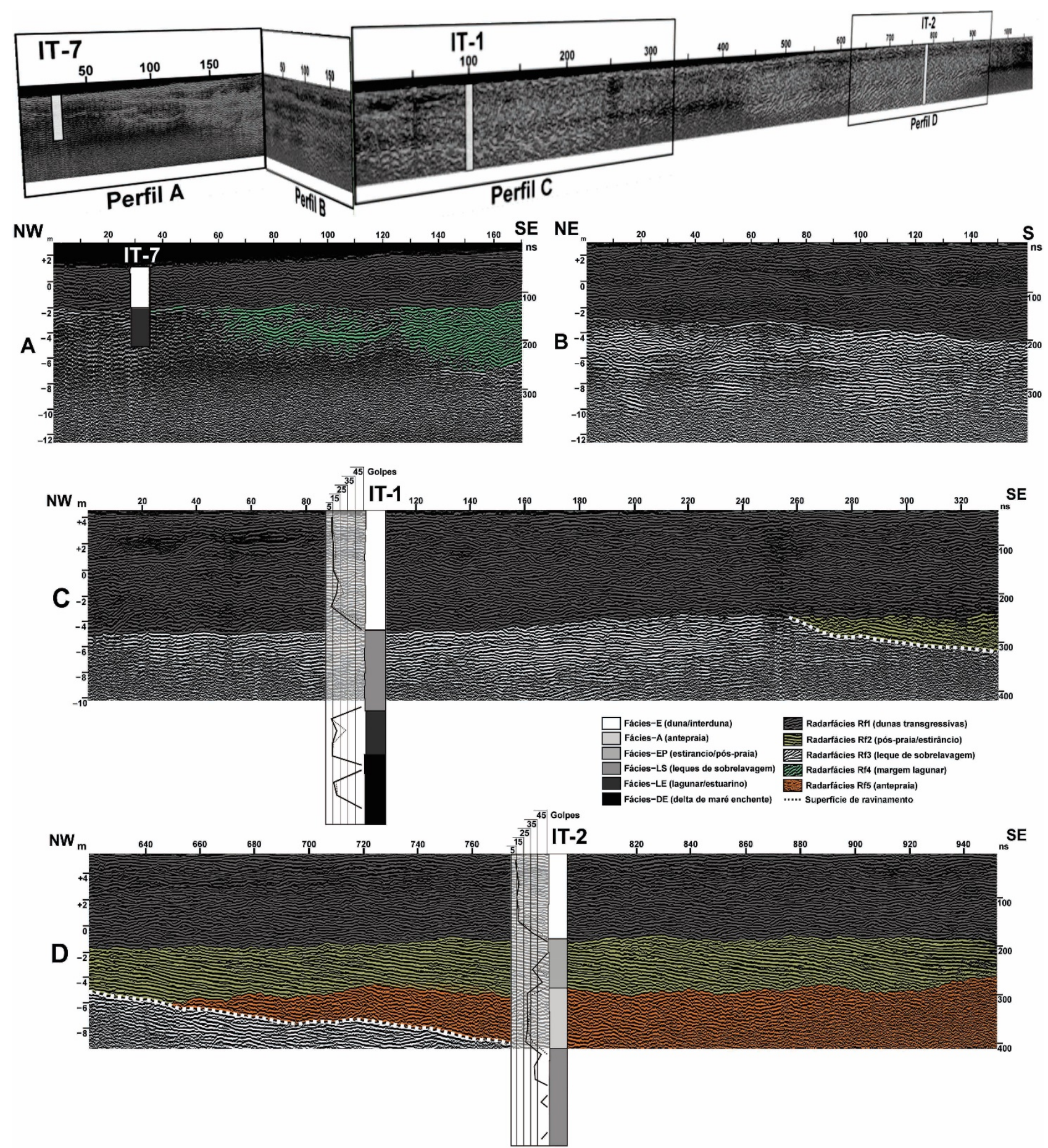

Figura 4 - Interpretação da perfilagem com GPR, indicando os perfis A-B-C-D. Anexo as sondagens encontram-se os dados geotécnicos (SPT) indicando o número de golpes do peso batente e sua correspondente resistência dinâmica a penetração do amostrador RAYMOND/TERZAGUI.

\section{Radarfácies Progradacionais}

No extremo SE do perfil-C, na mesma cota da Rf3 encontra-se um pronunciado refletor com mergulho em direção do oceano definindo a geometria característica da radarfácies Rf2 (Figuras 3 e 4). Este alvo a $480 \mathrm{~m}$ da margem lagunar atual e -4 m em relação ao NRM, marca o ponto de inversão da fase transgressiva para regressiva da barreira costeira na Praia de Itapeva. Este refletor delimita o extremo continental da SR. A continuidade destes refletores pode ser evidenciada no perfil-D cruzando a sondagem IT-2 executada sobre a fase regressiva desta barreira costeira. Neste setor, os refletores Rf2 apresentam-se contínuos, com alta amplitude e baixo ângulo (3-5) e mergulho em direção do oceano. Neste perfil, a radarfácies Rf1 apresenta-se sotoposta a Rf2 e esta última fácies ascende cerca de $2 \mathrm{~m}$ elevando-se em direção ao oceano até seu topo alcançar $-1 \mathrm{~m}$ abaixo do NRM (Figura 4). Neste ponto do perfil-D, abaixo dos refletores Rf2, encontra-se a radar fácies Rf5, composta de refletores nítidos na proximidade da interface transgressiva/regressiva e SR que 
perdem resolução em direção ao oceano.

\section{Sondagens Geológicas}

A sondagem IT-7 foi realizada na margem da Lagoa Itapeva a $+1 \mathrm{~m}$ acima do NRM, com 5,4 $\mathrm{m}$ e cruza duas fácies sedimentares. A fácies-LE (lagunar/estuarino) de 2,4 m é composta de areias finas, cinza escuro (5Y4/1), moderadamente selecionada, com lentes de silte onde os teores matéria orgânica atingem 2,4 \%. A -2,8 m do NRM uma lente siltosa de $5 \mathrm{~cm}$ foi submetida à datação ${ }^{14} \mathrm{C}(\mathrm{AMS})$ indicando a idade de $8.065 \pm$ 95 anos AP (tabela 1). No topo desta sondagem ocorre a fácies-ML (margem lagunar) de $3 \mathrm{~m}$ de espessura, predominantemente arenosa fina, com raízes, pobremente a bem selecionado e cinza claro (10YR6/2), com teores de matéria orgânica que alcançam $17 \%$ nos intervalos de granulometria siltosa grossa (phi 3,7).

A sondagem IT-1 encontra-se sobre a fase transgressiva da barreira costeira, com o topo na cota $+4,4 \mathrm{~m}$ e a base alcançando -20,6 $\mathrm{m}$ do NRM e cruza cinco fácies. A fácies-DE (delta de maré enchente) corresponde aos 5,5 $\mathrm{m}$ basais de areias finas, cor cinza (5Y7/2) de moderadamente a bem selecionadas e variando de muito compacta a pouco compacta com frequentes laminações de minerais pesados e teores de matéria orgânica (M.O.) de 0,5\%. Nesta fácies encontram-se macrofósseis dispersos e em laminações centimétricas, muito fragmentados, moderadamente abrasionados e muito bioturbados (95\% do total).

Foram identificados moluscos, equinóides e crustáceos. Entre os moluscos bivalves Adrana patagonica, Adrana ovalis, Amiantis purpurata, Donax gemmula, Mactra janeiroensis, Mactra patagonica, Ostrea puelchana. Gastrópodes foram presentes unicamente por rádulas não identificadas, equinoides por espinhos de ouriço e crustáceos por fragmentos de Cirripedia.

Na cota de 20,1 m do NRM duas valvas desarticuladas de $D$. gemmula foram submetidas à datação ${ }^{14} \mathrm{C}(A M S)$ indicando a idade de $7.865 \pm 115$ anos AP (tabela 1). Logo acima da fácies basal encontra-se a fácies-LE (lagunar/ estuarino) de difícil recuperação principalmente devido a sua baixa compactação. A amostra recuperada é basicamente arenosa fina, cinza (5Y7/2) pobremente selecionada e pouco compacta com $15 \%$ de silte e M.O. de $2 \%$.

A fácies-LS (leque de sobrelavagem) apresenta composição areia fina, cinza escuro (5GY4/1), moderadamente e bem selecionadas e que perfaz o perfil da compactação com valores sempre máximos (45 golpes). Lami-nações de minerais pesados e laminações de conchas de bivalves muito fragmentados são frequentes ao longo da fácies-LS. Teores de M.O. indicaram valores de 0,3-0,5\%. A fácies-E (duna/interduna) ocorre até o primeiro máximo de compactação em -4,6 m do NRM. Esta fácies é composta por areia fina bem a moderadamente selecionada, sem estruturas sedimentares, acinzentada $(10 Y 4 / 2)$ na base e gradando para bege (10YR5/4) no topo e pouco compacta. Na fácies-E as areias apresentam teores de M.O. de 4-6\% no entanto o topo desta fácies representa um ambiente interdunas atual e devido a isto existe um processo de pedogênese associado que resulta em cores bege escuro (10YR), intercalado com preto (N2)

A sondagem IT-2 posiciona-se sobre a fase regressiva da barreira costeira e está distante 3,7 $\mathrm{km}$ da praia oceânica atual. Esta sondagem aprofunda-se por $-24 \mathrm{~m}$ e cruza cinco fácies. A base da sondagem IT-2 corresponde à fácies-LS com espessura de $5 \mathrm{~m}$ de areias finas, cinza (5B5/1), moderadamente selecionada e muito compacta. A porcentagem de silte corresponde de 3,4\% e o teor de M.O. de 0,5\%. Laminações de minerais pesados são ocorrentes ao longo da fácies-LS. Sobrejacente à fácies-LS encontra-se a fácies-A (antepraia) com $9 \mathrm{~m}$ de espessura sendo arenosa fina, variando de cinza esverdeado (paleta 5G) a claro, moderadamente selecionada.

Tabela 1 - Idades das amostras de ${ }^{14} \mathrm{C}$.

\begin{tabular}{c|c|c|c|c|c}
\hline $\begin{array}{c}\text { Amostra/Número no } \\
\text { Laboratório }\end{array}$ & $\begin{array}{c}\text { Material } \\
\text { datado }\end{array}$ & $\begin{array}{c}\text { Prof. }^{\mathbf{c}} \\
\mathbf{( m )}\end{array}$ & $\begin{array}{c}\mathbf{1}^{\mathbf{1 3}} \mathbf{C} /{ }^{\mathbf{1 2}} \mathbf{C} \text { ratios } \\
\mathbf{( o / o 0})\end{array}$ & $\begin{array}{c}\text { Idade convencional } \\
\mathbf{( 1 4}^{\mathbf{1 4}} \mathbf{C} \text { anos AP) }\end{array}$ & $\begin{array}{c}\text { Idade calibrada } \\
\text { (anos AP) }^{\mathbf{b}}\end{array}$ \\
\hline IT-1 \#23/Beta - 285323 & Concha & $-20,1$ & NA & $7.490 \pm 40$ & $\mathbf{7 . 8 6 5} \pm \mathbf{1 1 5}$ \\
\hline IT-7/Beta - 298865 & Sed. orgânico & $-2,8$ & -19.1 & $7.250 \pm 40$ & $\mathbf{8 . 0 6 5} \pm \mathbf{9 5}$ \\
\hline
\end{tabular}

${ }^{\mathbf{a}}$ Beta Analytic Inc., Miami, Florida, USA. ${ }^{\mathbf{b}} 2$ sigma calibração (95\% probabilidade). ${ }^{\mathbf{c}}$ Profundidades de amostragem em relação ao NMM. ${ }^{\mathbf{d}}$ Bivalve articulado (posição de vida)

Lentes de lama conferem até $10 \%$ de silte e o teor de M.O. indica 0,7\%. Laminações de minerais pesados apresentam-se com alto ângulo nesta fácies. Acima está posicionada a fácies-EP de $4 \mathrm{~m}$ de espessura, arenosa fina, cinza claro (5GY6/1), moderadamente selecionada e 
compacta. Nesta fácies ocorrem apenas laminações plano-paralelas de minerais pesados e ausência de M.O. O limite superior da fácies-EP coincide com a ocorrência concreções ferruginosas, ausência de laminações e o primeiro máximo de compactação no perfil SPT.
O topo da sondagem IT-2 é indicado pela fácies-E (duna/interduna) arenosa fina, cor bege claro (10YR), gradando para marrom (N2) no topo, bem selecionada e pouco compacta. Ocorre material orgânico particulado e raízes que conferem até 3\% de M.O.

\section{DISCUSSÃO}

O imageamento do perfil GPR-1 (Figura 4) estendeu-se até a lâmina d'água da Lagoa Itapeva, permitindo a visualização do extremo continental (NO) dos leques de sobrelavagem representados pelas radarfácies $\mathrm{Rf} 3$, ou seja, do máximo avanço, em direção ao continente, das areias da barreira costeira em configuração transgressiva.

A base da unidade transgressiva, por sua vez, é ocupada por um ambiente deposicional correlato a um delta de maré enchente (fáciesDE) amostrado na sondagem IT-1, onde a base apresenta laminações de macrofósseis de moluscos, equinoides e cracas (cirripédios), todos com indícios de retrabalhamento. O modelo generalizado de deltas de maré de enchente foi proposto por Hayes (1979) sendo composto de cinco morfologias distintas: a rampa de inundação, o canal, o anteparo da vazante, o esporão de vazante e lobo de extravasamento. $\mathrm{O}$ registro obtido no presente estudo indica a base de um canal de ligação preenchido pela rampa de inundação. A diferença entre a fácies-LS e a fácies-DE reside nos aspectos tafonômicos da fácies DE, evidenciada pela sua elevada bioturbação (>95\%) e retrabalhamento.

Sua idade de $7.865 \pm 115$ anos AP foi obtida de duas valvas milimétricas de $D$. gemmula, cuja posição correspondeu à maior profundidade de amostragem deste estudo (Figura 5). No entanto esta espécie distribui-se em estirâncios de praias arenosas, salientando o retrabalhamento da face oceânica da barreira costeira em resposta a sua remobilização junto ao canal de ligação.

A fácies-DE compreende um intervalo arenoso, com expressiva laminação de minerais pesados e que gradam para areias melhor selecionadas e bem compactadas no topo da fácies. Esta seleção segundo Kraft et al. (1979); Moslow \& Heron (1979); Hennessy \& Zarillo (1987) é um indício do preenchimento do canal de ligação pelas areias melhores selecionadas do delta de maré enchente. A deposição da fáciesLE sobre o delta indica que o canal de ligação foi preenchido, provavelmente numa fase de relativa estabilidade da barreira costeira (Figura 5). Um modelo similar de fácies pode ser encontrado no trabalho de Hennessy \& Zarillo (1987) no canal de ligação Shinnecock em Long Island. Posteriormente a este preenchimento a barreira costeira assumiu uma nova fase transgressiva, onde na ausência de um canal de ligação o modo operante da transferência de sedimentos em direção do continente se deu via depósitos de leques de sobrelavagem (fácies-LS), sobrepondo as fácies lagunares previamente depositadas sobre o delta (Figura 5). Comparando-se as demais fácies sedimentares amostradas, a fáciesDE ocupa uma posição mais profunda (rebaixada) e ainda com indícios de elevada hidrodinâmica. O que se verifica é tendência de retenção da fração grossa (areia mais biodetritos) próximo ao eixo de um canal de ligação e corpo do delta de maré enchente (Swift, 1976; Kidwell, 1989; Siggerud et al., 2000). A elevada bioturbação dos macrofósseis presentes na fácies-DE indicam o abandono do eixo principal de um canal de ligação com posterior preenchimento por areias vinculadas à deposição do delta de maré enchente (Israel et al., 1987; Fitzgerald et al., 2012). No sentido do topo da fácies-DE ocorre um aumento quanto à seleção das areias sugerindo uma deposição relacionada a eventos de tempestade. $\mathrm{O}$ registro indiferenciado de depósitos de deltas de maré enchente e leques de sobrelavagem foi primeiramente reportado, no Rio Grande do Sul, por Travessas et al. (2005) na localidade de Tramandaí, cerca de $50 \mathrm{~km}$ ao sul da área de estudo. O desenvolvimento do complexo lagunar/estuarino (fácies-LE) sobre o delta de maré enchente (fácies-DE) pode indicar tanto a migração lateral do canal de ligação adjacente, como também seu fechamento (p.e. Simms et al., 2006).

No decorrer da TMP, o aumento do espaço de acomodação, criado pela elevação do nível do mar, transformou estes terrenos de retrobarreira outrora pantanosos em um sistema efetivamente 

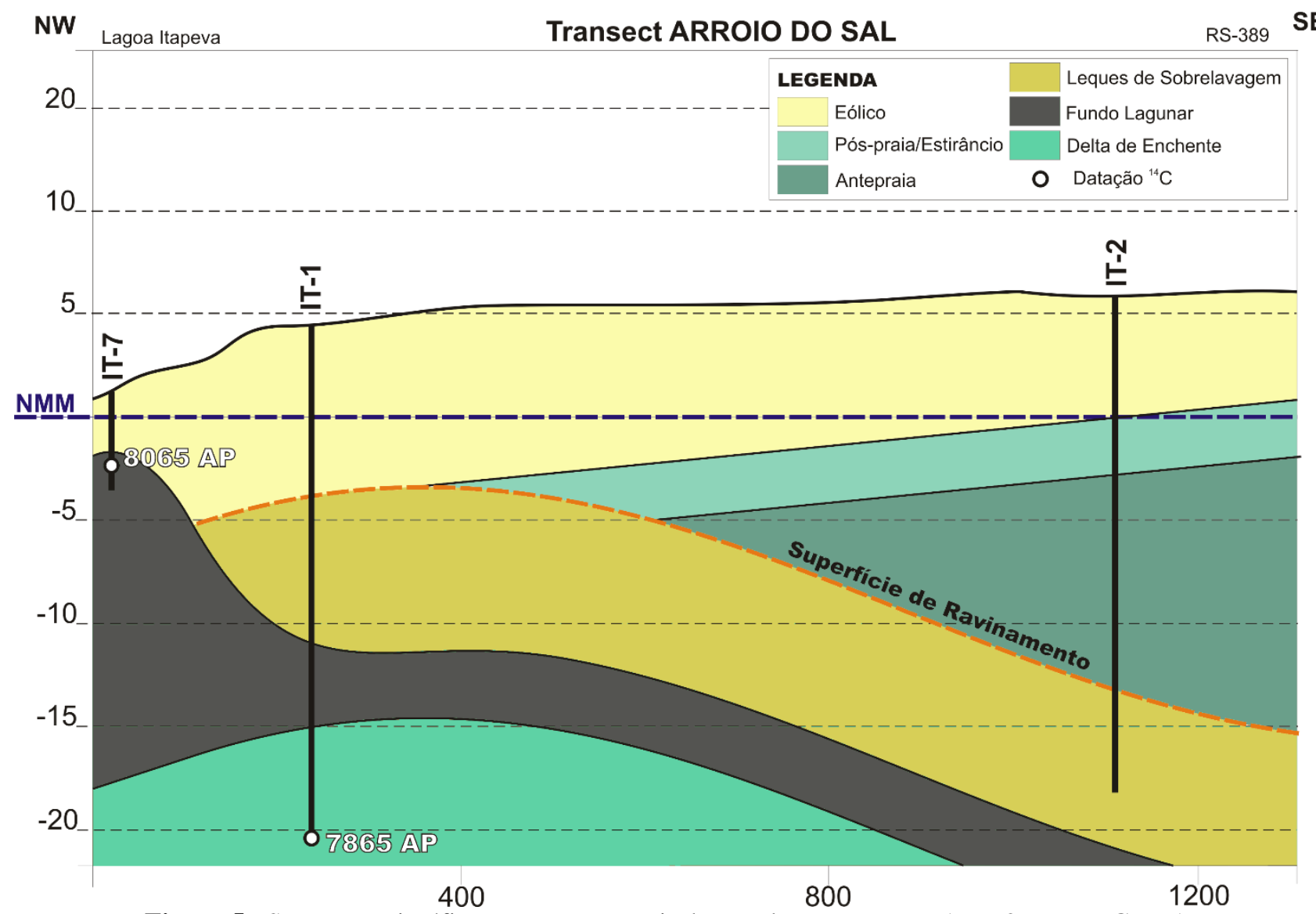

Figura 5 - Seção estratigráfica composta a partir das sondagens IT-7, IT-1, IT-2 e seção GPR-1.

lagunar/estuarino (fácies-LE). Provavelmente, esta inundação veio a se instalar primeiramente nos vales fluviais (fácies-DE) (depressões) e depois nas regiões de interflúvios (p.e. Boyd et al., 1992). Esta interpretação de franca conexão entre laguna e oceano deve-se à taxonomia dos espécimes amostrados na fácies-DE como também ao comportamento ainda em elevação do nível do mar há $7.865 \pm 115$ anos AP, permitindo à barreira costeira ser mais estreita e, portanto, possivelmente mais segmentada por canais de ligação (p.e. Kraft, 1971).

Na sondagem IT-1 a deposição dos leques de sobrelavagem (fácies-LS) sobre o ambiente lagunar/estuarino (fácies-LE) indica a migração da barreira transgressiva em direção ao continente. A proximidade das idades da fáciesLE e a fácies-DE, provavelmente deve-se à diferença quanto à composição do material datado, no caso, sedimento orgânico de $8.065 \pm$ 95 anos AP e conchas $7.865 \pm 115$ anos AP. No entanto, a diferença de cotas entre o topo da sedimentação lagunar/estuarino na fácies-LE na sondagem IT-7 (8.065 \pm 95 anos AP) e a base do delta de maré enchente na fácies-DE na sondagem IT-1 (7.865 \pm 115 anos AP) indica também os desníveis topográficos que constituíam a deposição sedimentar associadas à configuração transgressiva da barreira.

A arquitetura estratigráfica resultante do posicionamento da fácies-LE (8.065 \pm 95 anos AP) na mesma cota topográfica da fácies-LS confirma o término da fase transgressiva da barreira costeira e demonstra que, nos estágios finais da TMP, o compartimento da retrobarreira foi rapidamente preenchido (agradação lagunar) pela deposição da fácies-LE (Figura 5).

Sobre a fácies-LE (lagunar/estuarino) ocorre abruptamente a deposição da fácies-LS, que corresponde aos sedimentos praiais da barreira costeira que foram arrastados, em fluxo subaquoso, para a retrobarreira. Esta forma de deposição ocorre quando ondas de tempestade se sobrepõe à berma da praia, erodindo os sedimentos da superfície emersa da barreira costeira (Leatherman, 1977). São tidos como depósitos diagnósticos na identificação dos processos que agem na evolução de uma barreira costeira na fase de configuração transgressiva (Pierce, 1969; Dillon, 1970). Depósitos de leques de sobrelavagem geralmente alternam areias, fragmentos de conchas e minerais pesados indicando mudança de competência hidráulica durante as tempestades (Kochel \& Dolan, 1986). 
Comparando-se a fase transgressiva que originou estes depósitos, às maiores concentrações de minerais pesados na linha de costa atual do RS, verifica-se a correspondência aos atuais setores em transgressão (erosão) (Dillenburg et al., 2004; Lima et al., 2013).

Na seção GPR-1-A (Figura 4) verifica-se, no contato com os sedimentos lagunares, o empilhamento vertical dos refletores Rf3 da fácies-LS, com nítido mergulho dos refletores em direção ao continente. Isto indica que a barreira transgressiva assumiu sua última posição (máximo transgressivo) em direção ao continente e então passou a agradar juntamente com os depósitos lagunares pouco antes do início da fase progradacional posterior. Devido à fácies-LS resultar da erosão praial, estas areias agregam elevadas concentrações de minerais pesados tornando-se facilmente rastreáveis pelo método de GPR (Buynevich et al., 2004). A geometria destes refletores pode variar de mais suave (baixo ângulo) até mais abrupta (alto ângulo), ressaltando sua posição quanto à morfologia da barreira no momento da penetração do leque de sobrelavagem. Em outras palavras, os refletores de alto ângulo formam-se quando o fluxo encontra a margem lagunar e a lâmina d’água e desta forma a deposição se dá na forma de um típico washover-fan, na definição de Schwartz (1975), enquanto os refletores de baixo ângulo formam-se na retaguarda das dunas frontais sem alcançar o complexo lagunar.

Na seção GPR-1 perfil-A os refletores de baixo ângulo de mergulho são sucedidos por refletores com alto ângulo, o que implica inicialmente numa fase de aproximação da posição emersa da barreira em resposta à migração da barreira em direção ao continente, e posteriormente, uma fase de agradação lagunar em sincronismo com a agradação dos refletores Rf4. Esta sequência de fácies indica que todo o sistema laguna-barreira passou por um rápido empilhamento vertical (agradacional) nos estágios finais da TMP, e possivelmente representa o gatilho de inversão para um comportamento regressivo da barreira. A posição superior dos refletores Rf4 com mergulhos acentuados em direção ao continente é indicativo da margem lagunar, sendo suprida pelo campo eólico adjacente que começa a se formar sobre a barreira transgressiva. Este início de deposição eólica (radarfácies Rf1), no perfil-C, ainda sobre a barreira transgressiva, coincide provavelmente com o início da progradação da fácies-EP (Rf2). Este início de deposição da Rf2 indica a linha de costa relativa ao máximo transgressivo (sensu Curray, 1964) da barreira costeira, como também dimensiona a largura da barreira costeira neste tempo. Como a posição da Rf2 encontra-se distante $460 \mathrm{~m}$ da fácies-LE na sondagem IT-7 esta deveria ser a distância entre a laguna e a praia no momento de inversão transgressão/ regressão. Esta dimensão da barreira transgressiva é similar ao encontrado nas barreiras costeiras transgressivas, existentes atualmente no Golfo do México, que atualmente migram, em direção ao continente, como resultado da coalescência de leques de sobrelavagem (Morton \& Sallenger, 2003).

Além de sua dimensão, o topo da fácies-LS quando prolongado à SR fornece uma aproximação da geometria da barreira em sua configuração transgressiva, ou seja, o último perfil erosivo da praia/antepraia associado à fase transgressiva quando a barreira costeira se instala na sua atual posição, isolando o complexo lagunar na retaguarda na mesma (Figura 5). O critério diagnóstico no reconhecimento da SR deve-se ao truncamento erosivo dos refletores da radarfácies Rf3 pela radarfácies Rf2. Este truncamento indica também que o suprimento sedimentar, requerido para a migração da barreira transgressiva em direção ao continente, é obtido diretamente do substrato da própria barreira (Swift \& Thorne, 1991). Este padrão morfoestratigráfico da barreira transgressiva indica a resposta erosional, ou recuo da barreira (Sanders \& Kumar, 1975), ou mesmo o recuo da antepraia (Bruun, 1962; Swift, 1968), quando a migração da barreira em direção ao continente, trunca os depósitos préexistentes por ação de ondas, criando a SR (Plint \& Walker, 1987; Plint, 1988).

O sinal mais claro da elevação do NRM no transecto Itapeva, ocorre na sobreposição da fácies-DE (delta de enchente) pela fácies-LE (lagunar/estuarino), e esta última pela fácies-LS (leques de sobrelavagem). Estas três fácies juntas definem uma sequência transgressiva. Este padrão estratigráfico é comumente encontrado em localidades com barreiras costeiras transgressivas (p.e. Fisher, 1961; Dillon, 1970; Demarest \& Leatherman, 1985; Kochel \& Dolan, 1986; Amorosi, 1995; Cattaneo \& Steel, 2003; Buynevich et al., 2004; Lima et al., 2013). Cabe ressaltar ainda que relação espacial entre a base dos sedimentos holocênicos (fácies-DE) e a 
trajetória da SR estabelece o potencial de preservação destes depósitos transgressivos (Belknap \& Kraft, 1981; 1985). A geometria da fácies-LE indica que o estabelecimento da barreira transgressiva, na sua atual posição, envolveu uma fase agradacional lagunar que fechou os canais de ligação presentes. Este evento cancelou a transferência dos sedimentos ao longo da componente transversal à costa, via canais de ligação permanecendo somente a deposição de leques de sobrelavagem, modificando a relação entre acomodação e suprimento sedimentar neste setor costeiro (Sloss, 1962; Curray, 1964; Swift, 1975; Vail et al., 1977). Assim, conforme o fluxo sedimentar tornou-se mais restrito à face oceânica da barreira, a taxa de aporte de sedimentos, por fim, superou a acomodação sedimentar, dando início à progradação costeira, neste caso, uma situação de regressão normal. Desta forma, a interface transgressiva/regressiva ficou preservada em subsuperfície como uma superfície de ravinamento.

$\mathrm{Na}$ sondagem IT-7 a amostra sedimentar datada na fácies-LE encontra-se sobrelevada +1,8 m em relação ao início do registro da radarfácies Rf2, fato que fortalece a presença de um campo eólico sobre a barreira transgressiva bloqueando as águas lagunares há aproximadamente $8.065 \pm 95$ cal. anos AP. Esta posição da Rf2 representa o início do registro regressivo (progradacional), e ocorre associada a refletores na cota de $-4 \mathrm{~m}$ em relação ao NRM. Estes refletores elevam-se gradativamente na direção do oceano e na sondagem IT-2 o topo da fácies-EP alcança a cota de $0 \mathrm{~m}$. Como esta posição representa o limite SE deste transecto, não é possível definir uma posição relativa à cronologia do máximo eustático (máxima elevação da fácies-EP), somente infere-se que ela ocorra a SE da sondagem IT-2 e da seção GPR1, perfil-D. Esta ascensão topográfica dos depósitos do estirâncio/pós-praia em direção ao oceano (SE), indica que o momento de inversão transgressivo/regressivo, divergiu do máximo eustático ocorrido há 6.000-5.000 anos AP (Martin et al., 2003; Angulo et al., 2006). Assim, a inversão aprisionou o registro do máximo transgressivo e, portanto, da interface trans- gressão/regressão a oeste (em direção ao continente) da linha de costa no máximo eustático. Isto indica que a progradação inicial da barreira correspondeu a uma regressão normal da linha de costa. Já o registro correlacionável ao nível de mar máximo da TMP (máximo eustático), ficou preservado na fase regressiva, correspondendo à máxima elevação dos depósitos praiais (fácies-EP ou Rf2), no entanto não evidenciados neste estudo. A idade para o início desta fase regressiva, foi obtida por Lima (2012) a partir do registro da sedimentação de antepraia, depositada sobre a SR ao norte da Praia de Itapeva datada em $7.205 \pm 55$ anos AP.

Imediatamente acima dos leques de sobrelavagem (Rf3) ocorre à deposição da Rf1, tendo seu desenvolvimento vinculado tanto à fase retrogradacional como à progradacional. Este ambiente eólico ocupou primeiramente superfície da barreira transgressiva e depois se expandiu para a barreira regressiva enquanto o nível do mar continuava em elevação, durante a fase de regressão normal da barreira. O desenvolvimento da radarfácies Rf1 foi profundamente influenciada por flutuações do nível d'água lagunar que, na ausência dos canais de ligação, permaneceram sobreelevados em relação ao nível do mar. Prova disto são os altos ângulos de refletores da Rf3 e Rf1 na proximidade da margem lagunar.

Nos perfis topográficos executados foi observado a tendência de elevação em direção ao centro da barreira (RS-389) alcançando cotas de +9 m. Segundo HESP et al. (2007), isto indica uma agradação e progradação da barreira, ocorrida entre 8.000-7.000 anos AP e 5.600 cal. anos AP (nível de mar mais alto da TMP). Isto corrobora diretamente com os aspectos topográficos da fácies-EP e da fácies-LS indicando que esta agradação se inicia ainda na fase transgressiva da barreira. Este início de desenvolvimento do sistema eólico se deu sobre os depósitos de leques de sobrelavagem, e foi fundamental na evolução da barreira, elevando sua altura e protegendo a retrobarreira dos processos de sobrelavagem (p.e., Donnelly, 2007; Williams \& Flanagan, 2009; Priestas \& Fagherazzi, 2010).

\section{CONCLUSÕES}

O presente estudo contempla a evolução da barreira costeira holocênica no setor TorresCurumim no litoral norte do Rio Grande do Sul. Sua origem se deu a partir da implantação de uma unidade transgressiva basal (retrogradacional) atribuída à subida NRM por ocasião da TMP, sendo seguida de uma regressiva (progradacional). A transição entre estas unidades antecedeu o ápice 
da TMP, indicando uma situação de elevado suprimento sedimentar (suprimento $>$ acomodação), o que resultou, durante a progradação da barreira costeira, uma fase inicial de regressão normal.

A evolução holocênica desta barreira costeira se deu de duas formas distintas: uma responsável pela retrogradação da barreira de modo que depósitos de leques de sobrelavagem (washover), deltas de maré enchente e dunas transgressivas representaram os modos operantes da transferência de sedimentos em direção ao continente; a segunda responsável pela progradação da barreira onde depósitos do pós-praia/estirâncio, antepraia progradacional e cordões de dunas frontais representaram a transferência de sedimentos em direção do oceano.

O primeiro registro da TMP no setor costeiro da Praia de Arroio do Sal ocorreu pelo estabelecimento de ambiente lagunar/estuarino (fácies-LE) e de forma síncrona um ambiente de delta de maré enchente, que sob franca elevação do nível do mar recobriu os ambientes prétransgressão (topografia antecedente) por volta de 8.000 anos AP. Os táxons identificados nestes ambientes deposicionais indicam que a morfologia da barreira adjacente se apresentava segmentada por canais de ligação, e que na retrobarreira existia ao menos uma descarga fluvial importante viabilizando uma hidrodinâmica lagunar/estuarina. A arquitetura estratigráfica resultante do posicionamento da fácies-LE na mesma cota topográfica da fácies-LS confirma o término da fase transgressiva da barreira costeira e demonstra que, próximo aos estágios finais da TMP, todo o complexo laguna-barreira costeira sofreu empilhamento vertical (agradacional) e que isto possivelmente representou o gatilho da inversão para um comportamento regressivo da barreira.

O truncamento erosivo dos refletores associados a radarfácies leques de sobrelavagem (Rf3) define a geometria da interface transgressiva/regressiva da barreira costeira, evidenciando a máxima incursão, continente adentro da superfície de ravinamento. Ou seja, o contato entre a radarfácies pós-praia /estirâncio (Rf3) e SR define a posição relativa ao máximo transgressivo da linha de costa (sensu Curray 1964). Sobre esta interface se estabelece o primeiro registro da fase progradacional da barreira costeira correspondendo a uma regressão normal da linha de costa, registrando, na ascensão das cotas topográficas da fácies-EP e radarfácies Rf2, o comportamento em elevação do nível do mar até ser atingido o ápice da TMP (aproximadamente $+2,1 \mathrm{~m}$ acima do NRM).

\section{REFERÊNCIAS}

AMOROSI, A. Glaucony and sequence stratigraphy: a conceptual framework of distribution in siliciclastic sequences. Journal of Sedimentary Research, v. 4, p. 419-425, 1995.

ANGULO, R.J.; LESSA, G.C.; SOUZA, M.C.; A critical review of Mid- to Late Holocene sealevel fluctuations on the eastern Brazilian coastline. Quaternary Science Review, v. 25, p. 486-506, 2006.

ANTHONY, D. \& MOLLER, I. The geological architecture and development of the Holmsland Barrier and Ringkobing Fjord area, Danish North Sea Coast. Geografisk Tidsskrift, Danish Journal of Geography, v. 102, p. 27-36, 2002.

BARBOZA, E.G.; DILLENBURG, S.R.; ROSA, M.L.C.C.; TOMAZELLI, L.J.; HESP, P.A. Ground-penetrating radar profiles of two Holocene regressive barriers in southern Brazil. Journal of Coastal Research, v. SI 56, p. 579-583, 2009.

BELKNAP, D.F. \& KRAFT, J.C. Influence of antecedent geology on stratigraphic preservation potential and evolution of Delaware's barrier systems. Marine Geology, v. 63, p. 235- 262, 1985.

BELKNAP, D.F. \& KRAFT, J.C. Preservation potential of transgressive coastal lithosomes on the U.S. Atlantic shelf. Marine Geology, v. 42, p.429-442, 1981.

BOYD, R.; DALRYMPLE, R.; ZAITLIN, B.A. Classification of clastic coastal depositional environments. Sedimentary Geology, v. 80, p. 139-150, 1992.

BRIDGE J.S.; ALEXANDER J.; COLLIER R.E.L.; GAWTHORPE R.L.; JARVIS J. Ground-penetrating radar and coring used to study the large-scale structure of point-bar deposits in three dimensions. Sedimentology, v. 42, p. 839-852, 1995.

BRISTOW, C.S.; CHROSTON P.N.; BAILEY I.D. The structure and development of foredunes on a locally prograding coast: insights from ground-penetrating radar surveys, Norfolk.
Sedimentology, v. 47, p. 923-944, 2000.

BRUUN, P. Sea-level rise as a cause of shore erosion. Proceedings of the American Society of Civil Engineers. Journal of the Waterways and Harbors Division, v. 88, p. 117-130, 1962.

BUYNEVICH, I.V.; FITZGERALD, D.M.; HETEREN, V. Sedimentary records of intense storms in Holocene barrier sequences. Maine, USA: Marine Geology, v. 210, p. 135-148, 2004.

CALDAS L.H.O.; OLIVEIRA Jr J.G.; MEDEIROS W.E.; STATTEGER K.; VITAL H. Geometry and evolution of Holocene transgressive and regressive barriers on the semi-arid coast of $\mathrm{NE}$ Brazil. Geo-Marine Letters, v. 26, p. 249-263, 2006.

CALLIARI, L.J.; TOZZI, H.M.; KLEIN, A.H. Erosão associada a marés meteorológicas na costa sul-rio-grandense. In: CONGRESSO BRASILEIRO DE GEOLOGIA 34, 1996, Salvador. Anais...Salvador: Sociedade Brasileira de Geologia, 1996, v. 1. p. 430-434.

CARTER, R.W.G. \& ORFORD, J.D. The morph dynamics of coarse clastic beaches and barriers: a short and long-term perspective. Journal of Coastal Research, v. 15, p. 158-179, 1993.

CATTANEO, A. \& STEEL, R.J. Transgressive deposits: a review of their variability. Earth-Science Reviews, v. 62, p. 187-228, 2003. CORREA, I.C.S.; MARTINS, L.R.; KETZER, J.M., ELIAS, A.R.D. A Plataforma Continental Sul e Sudeste Brasileira Durante O Holoceno. In: VII CONGRESSO LATINOAMERICANO DE CIENCIAS DEL MAR, 1995, Mar del Plata-Argentina. Anais... Mar del Plata-Argentina, 1995, v. 1, p. 56-56.

CURRAY, J.R. Transgressions and regressions. In: Miller, R.L. (Ed.), Papers in Marine Geology. Macmillan, New York, p. 175- 203, 1964. 
DEMAREST, J.M. \& LEATHERMAN, S.P. Mainland influence on coastal transgression: Delmarva Peninsula. Marine Geology, v. 63, p. 19-33, 1985.

DILLENBURG, S.R.; BARBOZA, E.G.; HESP, P.A.; ROSA, M.L.C.C. Ground Penetrating Radar (GPR) and Standard Penetration Test (SPT) records of a regressive barrier in southern Brazil. Journal of Coastal Research, v. SI 64, p. 651-655, 2011.

DILLENBURG, S.R.; ROY, P.S.; COWELL, P.J.; TOMAZELLI, L.J. Influence of antecedent topography on coastal evolution as tested by the shoreface translation-barrier model (STM). Journal Coastal Research, v. 16, p.71-81, 2000.

DILLENBURG, S.R.; TOMAZELLI, L.J.; BARBOZA, E.G. Barrier evolution and placer formation at Bujuru southern Brazil. Marine Geology, v. 203, p. 43-56, 2004.

DILLON, W.P. Submergence effects on a Rhode Island barrier lagoon and inferences on migration of barriers, Journal of Geology, v. 78, p. 94-106, 1970.

DONNELLY, C. Morphologic Change by Over wash Establishing and Evaluating Predictors. Journal of Coastal Research, SI 50 (Proceedings of the 9th International Coastal Symposium), Gold Coast, Australia p. 520-526, 2007.

FISHER, A.G. Stratigraphyc record of transgressive seas in the light of sedimentation on the Atlantic coast of New Jersey: AAPG, v. 45, p. 1656-1666, 1961

FITZGERALD, D.; BUYNEVICH, I.; HEIN, C. Morph dynamics and facies architecture of tidal inlets and tidal deltas. In: Davis R, Dalrymple R (eds) Principles of tidal sedimentology. Springer, New York, p. 301-333, 2012.

FITZGERALD, D.M. \& VAN HETEREN, S. Classification of paraglacial barrier systems: Coastal New England, USA. Sedimentology, v. 46, p. 1083-1108, 1999.

FOLK, R.L. \& WARD, W.C. Brazos River Bar: Study and significance of grain size parameters. Journal Sedimentary Petrology, v. 27, n. 1, p. 03-26, 1957.

FONTANA, R.L. Geotectônica e Sismoestratigrafia da Bacia de Pelotas e Plataforma de Florianópolis. Porto Alegre, 1996 214 p. Tese de Doutorado em Geociências, Instituto de Geociências, Universidade Federal do Rio Grande do Sul.

GALLOWAY, W.E. \& HOBDAY, D.K. Terrigenous Clastic Depositional Systems: Applications to Petroleum, Coal and Uranium Exploration. New York, Springer-Verlag, p. 423, 1983.

HAYES, M.O. Barrier island morphology as a function of tidal and wave regime. In: LEATHERMAN, S. (ed.), Barrier Islands, from the Gulf of St. Lawrence to the Gulf of Mexico. New York: Academic, p. 1-27, 1979.

HENNESSY, J.T. \& ZARILLO, G.A. The inter-relation and distinction between flood tidal delta and was hover deposits in a transgressive barrier island. Marine. Geology, v. 78, p. 3556, 1987.

HESP, P.A.; DILLENBURG, S.R.; BARBOZA, E.G.; CLEROT, L.C.P.; TOMAZELLI, L.J. e AYUP-ZOUAIN, R.N., Morphology of the Itapeva to Tramandaí transgressive dunefield barrier system and mid- to late Holocene sea level change. Earth Surface Processes and Landforms, v. 32, p. 407-414, 2007.

HUGHEM, K.A.; MIKE, GL.; BAILLIE, E.B.; BECK, J.W. Marine04 Marine Radiocarbon Age Calibration, 0-26 Cal kyr BP. Radiocarbon, v. 46, n. 3, p. 1059-1086, 2004.

ISRAEL, A.M.; ETHRIDGE, F.G.; ANDESTES, E.L. A sedimentologic description of amicrotidal, flood-tidal delta, San Luis Pass, Texas: Journal of Sedimentary Petrology, v. 57, p. 288-300.

JOL, H.M. \& SMITH, D.G. Ground penetrating radar of northern lacustrine deltas: Canadian Journal of Earth Sciences, v. 28, p. 1939-1947, 1987.

JOL, H.M.; SMITH, D.G.; MEYERS, R.A. Digital Ground Penetrating Radar (GPR): A New Geophysical Tool for Coastal Barrier Research (Examples from the Atlantic, Gulf and Pacific Coasts, U.S.A). Journal of Coastal Research, v. 12, n. 4, p. 960-968, 1996.

KIDWELL, S.M. Stratigraphic condensation of marine transgressive records: Origin of major shell deposits in the Miocene of Maryland: Journal of Geology, v. 97, p. 1-24, 1989.

KOCHEL, R.C. \& DOLAN, R. The role of over wash on a midAtlantic coast barrier island. Journal of Geology, v. 94, p. 902906, 1986.

KRAFT, J.C. \& JOHN, C.J. Lateral and vertical facies relations of transgressive barrier: AAPG, v. 63, p. 2145-2163, 1979.

KRAFT, J.C. Sedimentary facies patterns and geologic history of a Holocene marine transgression. AAPG, v. 82, p. 2131-2158, 1971. KRAFT, J.C.; ALLEN, E.A.; BELKNAP, D.F.; JOHN, C.J.; MAURMEYER, E.M. Processes and morphologic evolution of an estuarine and coastal barrier system. In: LEATHERMAN, S.P. (Edr), Barrier Islands from the Gulf of St. Lawrence to the Gulf of Mexico. Academic Press, New York, p.149-183, 1979.

LEATHERMAN, S.P. \& WILLIAMS, A.T. Lateral textural grading in over wash sediments. Earth Surf. Proc. Landforms v. 2, p. 333-341, 1977.

LEATHERMAN, S.P. Barrier dynamics and landward migration with Holocene sea-level rise. Nature v. 301, p. 415-418, 1983.

LEATHERMAN, S.P. Coastal geomorphic applications of ground penetrating radar. Journal of Coastal Research, v. 3, n. 3, p. 397-399, 1987.

LIMA, L.G. Estratigrafia e evolução holocênica de uma barreira costeira transgressiva/regressiva, litoral Norte do Rio Grande do Sul. Porto Alegre, 2012, 116 p. Tese (Doutorado), Instituto de Geociências, Univ. Fed. do Rio Grande do Sul

LIMA, L.G.; DILLENBURG, S.R.; MEDEANIC, S.; BARBOZA, E.G.; ROSA, M.L.C.C.; TOMAZELLI, L.J.; DEHNHARDT, B.A. \& CARON, F. Sea-level rise and sediment budget controlling the evolution of a transgressive barrier in southern Brazil. Journal of South American Earth Sciences, v. 42, p. 27-38, 2013.

MARTIN, L.; DOMINGUEZ, J.M.L.; BITTENCOURT, A.C.S.P. Fluctuating Holocene sea levels is eastern and southeastern Brazil: evidence from a multiple fossil and geometric indicators. Journal of Coastal Research, v. 19, p. 101-124, 2003.

MARTINS, L.R.; URIEN, C.M.; EICHLER, B.B. Distribuição dos sedimentos modernos da Plataforma Continental SulBrasileira e Uruguaia. In: CONGRESSO BRASILEIRO DE GEOLOGIA, 21, 1967, Curitiba. Anais. Curitiba: Sociedade Brasileira de Geologia, 1967, v.1, p. 29-43.

MEYERS, R.A.; SMITH, D.G.; JOL, H.M. Ground penetrating radar investigation of the internal structure of a Pacific coast barrier spit: Abstr. with Prog., Geol. Soc. Am., p. 26, 69, 1994. MOLLER, I. \& ANTHONY, D. A GPR study of sedimentary structures within a transgressive coastal barrier along the Danish North Sea coast. In: BRISTOW, C.S. \& JOL, H.M. (Eds) Ground Penetrating Radar in Sediments, Geological Society of London, Special Publications, v. 211, p. 55-65, 2003. MORTON, R.A. \& SALLENGER, A.H. Jr. Morphological impacts of Extreme Storms on Sandy Beaches and Barriers. West Palm Beach, Florida. Journal of Coastal Research, v. 19, n. 3, p. 560-573, 2003.

MOSLOW, T.F. \& HERON Jr., S.D. Quaternary evolution of Core Banks, North Carolina: Cape Lookout to New Drum Inlet. In: S.P. Leatherman (Editor), Barrier Islands. Academic Press, New York, N.Y., p.211-236, 1979.

MOTTA, V.F. Estudo em modelo reduzido da regulamentação da embocadura lagunar de Tramandaí (Rio Grande do Sul). Porto Alegre, 1967. Tese (Doutorado), Instituto de Pesquisas Hidráulicas, Universidade Federal do Rio Grande do Sul.

MURAKOSHI, N. \& MASUDA, F. A depositional model for a flood tidal delta and was hover sands in the late Pleistocene Paleo-Tokio Bay, Japan. In: REINSON, G.E.; ZAITLIN, B.A.; RAHMANI, R.A. (Eds.), Clastic Tidal Sedimentology. Can. Soc. Pet. Geol., v. 16, p. 219-226, 1991.

NEAL, A. \& ROBERTS, C.L. Applications of groundpenetrating radar (GPR) to sedimentological, geomorphological and geoarchaeological studies in coastal environments Geological Society, London, Special 
Publications, v. 175, p. 139-171, 2000.

NEAL, A. Ground-penetrating radar and its use in sedimentology: principles, problems and progress. EarthScience Reviews, n. 66, p. 261-330, 2004.

NEAL, A.; RICHARDS, J.; PYE, K. Sedimentology of coarse clastic beach ridge deposits, Essex, Southeast England; Sedimentary Geol. v. 162, p. 167-198, 2003.

NIMER, E. Clima. In: IBGE (ed.) Geografia do Brasil, Região Sul. Rio de Janeiro, SERGRAF-IBGE. p. 35-79, 1977.

NIMER, E. Clima. In: IBGE. Geografia do Brasil: região Sul. v. 2. Rio de Janeiro: Instituto Brasileiro de Geografia e Estatística, p. 113 - 150, 1990.

OERTEL, G.F. The barrier island system. Marine Geology, v. 63, p. 1-18, 1985.

PARISE, C.K.; CALLIARI, L.J; KRUSCHE, N. Extreme storm surges in the south of Brazil: Atmospheric conditions and shore erosion. Brazilian Journal of Oceanography, v. 57, p. 175188, 2009.

PIERCE, J.W. Sediment budget along a barrier island chain. Sedimentary Geology, v. 3, p. 5-16, 1969.

PLINT, A.G. \& WALKER, R.G. Morphology and origin of an erosional surface cut into the Bad Heart Formation during major sea-level change, Santonian of west-central Alberta, Canada. Journal of Sedimentary Petrology, v. 57, p. 639-650, 1987.

PLINT, A.G. Sharp-based shore face sequences and "'offshore bars"' in the Cardium formation of Alberta: their relationship to relative changes in sea level. In: WILGUS, C.K.; HASTINGS, B.S.; KENDALL, C.G.ST.C.; POSAMENTIER, H.W.; ROSS, C.A.; VAN WAGONER, J.C. eds., Sea-Level Changes-An Integrated Approach: SEPM, Special Publication, v. 42, p. 357-370, 1988.

PRIESTAS, A.M. \& FAGHERAZZI, S. Morphological Barrier Island Changes and Recovery of Dunes after Hurricane Dennis, St. George Island, Florida. Geomorphology, v. 114, p. 614626, 2010.

REIMER P.J. IntCal04 terrestrial radiocarbon age calibration, 0 26cal kyr BP. Radiocarbon, v. 46, p.1029-1058, 2004.

SANDERS, J.E. \& KUMAR, N. Evidence of shoreface retreat and in-place "drowning" during Holocene submergence of barriers, shelf off Fire Island, New York. Geological Society of America Bulletin v. 86, p. 65-76, 1975.

SCHWARTZ, R.K. Bedform and stratification characteristics of some modern small-scale washover sand bodies: Sedimentology, v. 29, p. 835-849, 1982.

SCHWARTZ, R.K. Nature and genesis of some storm washover deposits. CERC Technical Memo 61, U.S. Army Corps of Engineers, 69 pp., 1975.

SHUKLA, S.B.; PATIDAR, A.K.; BHATt, N. Application of GPR in study ofshallow subsurface sedimentary architecture of Modwa spit, Gulf of Kachchh. Journal of Earth System \&Science, v. 117, n. 1, February 2008, p. 33-40, 2008.

SIGGERUD, E.I.H.; STEEL, R.J.; POLLARD, J. Bored pebbles and ravinement surface clusters in a transgressive systems tract, Sant Llorenc del Munt fan-delta complex, SE Ebro Basin, Spain. Sedimentary Geology, v. 138, p.1610-177, 2000.

SIMMS, A.R.; ANDERSON, J.B.; BLUM, M. Barrier-island aggradation via inlet migration: Mustang Island, Texas. Sedimentary Geology, v.187, p. 105-125, 2006.

SLOSS, L.L. Stratigraphic models in exploration: Journal of Sedimentary Petrology, v. 32, p. 415-422, 1962.

SMITH, D.G.; MEYERS, R.A.; JOL, H.M. Sedimentology of an upper-mesotidal (3.7 m) Holocene barrier, Willapa Bay, SW Washington, U.S.A. Journal of Sedimentary Research, v. 69, p. 1290-1296, 1999.

SWIFT, D.J.P. \& THORNE, J.A. Sedimentation on Continental Margins, I - a general model for shelf sedimentation. Special Publication of the International Association of Sedimentologists. v. 14, p. 3-31, 1991.
SWIFT, D.J.P. Coastal erosion and transgressive stratigraphy. Journal of Geology, v. 76, p. 444-456, 1968.

SWIFT, D.J.P. Continental shelf sedimentation. In: Stanley, D., Swift, D.J.P. (Eds.), Marine Sediment Transport and Environmental Management. John Wiley \& Sons, New York, p. $311-350,1976$.

SWIFT, D.J.P. Tidal sand ridges and shoal retreat massifs. Marine Geology, v. 18, p. 105-134, 1975.

SWITZER, A.D.; BRISTOW, C.S.; JONES, B.G. An erosional signature for large-scale was hover identified using ground penetrating radar on a small Holocene barrier from the southeast Australian coast. Sedimentary Geology, v. 183, p. 145-56, 2006.

TALMA, A.S. \& VOGE, L,J.C. A Simplified Approach to the Calibration of Radiocarbon Dates. Radiocarbon, v. 35 n.2, p. 317-322, 1993.

TOMAZELLI, L.J. \& VILLWOCK, J.A. Considerações sobre o ambiente praial e à deriva litorânea de sedimentos ao longo do litoral norte do Rio Grande do Sul, Brasil. Instituto de Geociências, UFRGS. Porto Alegre, Pesquisas, v.19, p. 3-12, 1992.

TOMAZELLI, L.J. \& VILLWOCK, J.A. Quaternary Geological Evolution of Rio Grande do Sul Coastal Plain, Southern Brazil. An. Acad. Bras. Ciências, v. 68, p. 373-382, 1996.

TOMAZELLI, L.J. O Regime dos Ventos e a Taxa de Migração das Dunas Eólicas Costeiras do Rio Grande do Sul, Brasil. Pesquisas, v. 20, n. 1, p. 18-26, 1993.

TRAVESSAS, F.A.; DILLENBURG, S.R.; CLEROT, L.C.P. Estratigrafia e evolução da barreira holocênica do Rio Grande do Sul no trecho Tramandaí-Cidreira. Boletim Paranaense de Geociências, v. 53, p. 57-73, 2005.

VAIL, P.R.; MITCHUM, J.R.; TODD, R.G.; WIDMIER, J.M.; THOMPSON III, S.; SANGREE, J.B.; BUBB, J.N.; HATLELID, W.G. Seismic stratigraphy and global changes of sea-level. In: PAYTON, C.E. (Ed.), Seismic Stratigraphy-Applications to Hydrocarbon Exploration. American Association of Petroleum Geologists Memoir, v. 26, p. 49-212, 1977.

VAN HETEREN, S.; FITZGERALD, D.M.; BARBER, D.C.; KELLEY, J.T.; BELKNAP, D.F., Volumetric analysis of a New England barrier system using ground- penetrating radar and coring techniques. Journal of Geology, v. 104, p. 471- 483, 1996.

VAN OVERMEEREN, R.A. Radar facies of unconsolidated sediments in The Netherlands: a radar stratigraphy interpretation method for hydrogeology. Journal. Appl. Geophycs, v. 40, p.1-18, 1998.

VILLWOCK, J.A.; TOMAZELLI, L.J.; LOSS, E.L.; DEHNHARDT, E.A.; BACHI, F.A.; DEHNHARDT, B.A. Geology of the Rio Grande do Sul Coastal Province. In: Rabassa, J. (ed.). Quaternary of South America and Antartic Peninsula. A.A. Balkema, Rotterdam. v. 4, p. 79-97, 1986.

WETZEL, R.G.W.B. Sauders Company, Philadelphia, London, and Toronto. Xii. Limnology, 743 p. 1975.

WILLIAMS, H.F.L \& FLANAGAN, W.M. Contribution of Hurricane Rita storm surge deposition to long-term sedimentation in Louisiana coastal woodlands and marshes. Journal of Coastal Research, Special Issue v. 56, p. 1671$1675,2009$.

WOODROFFE, C.D. Coasts: Form, Process and Evolution. Cambridge University Press. 623 p. 2002.

Submetido em 3 de outubro de 2019 Aceito para publicação em 7 de maio de 2020 